\title{
Development of a Code of Practice and Indicators for Quality Management of Official Statistics in Thailand
}

\author{
Titirut Mekbunditkul ${ }^{1, *}$ and Sorachai Phisalbutr ${ }^{2}$ \\ ${ }^{1}$ Research Service Center, Dhurakij Pundit University, Bangkok, Thailand \\ ${ }^{2}$ Retired Government Official, Bangkok, Thailand
}

\begin{abstract}
This paper is concerned with the National Statistical Office of Thailand, and constructs a Code of Practice and indicators for quality management of official statistics in Thailand. Official statistics for quality management from three international agencies include the United Nations Statistics Division (UNSD), European Statistical System (Eurostat), and International Monetary Fund (IMF). Factor analysis is used to determine the important indicators and their respective weights. The research shows that a Code of Practice for quality management of official statistics in Thailand should be comprised of 9 rules and 35 common indicators.
\end{abstract}

Keywords: Code of Practice, Rules, Indicators, Official Statistics, Quality Management.

\section{INTRODUCTION}

International organizations, as well as many countries, have official statistical management standards, depending on the context of that country and international organization. In Europe, for example, international organizations that have a large official statistical management system covering many countries, such as the United Nations Statistics Division (UNSD), whose mission is to assist national statistic development, require a National Statistical system for all members that can support the accurate and reliable production of official statistics. These can then be used for developing the country.

The standard or principle used by the UNSD in producing Official Statistics are based on The Conference of European Statisticians, which developed and adopted the Fundamental Principles of Official Statistics, in 1991, where they agreed to jointly develop a Fundamental Principles of Official Statistics which was to be implemented in 1992. Later, statisticians from all over the world recognized the importance of the fundamental principles and, in 1994, the UNSD declared the acceptance of the fundamental principles with minor adjustments to the introduction and announced the principles under the name of The United Nations Fundamental Principles of Official Statistics. At present, the UNSD is using a generic framework for quality assurance called "The Generic National Quality Assurance Framework (NQAF)" (The Expert Group on NQAF 2012), which many

*Address of correspondence to this author at the Research Service Center, Dhurakij Pundit University, Bangkok, Thailand; Tel: (66)2-954-7300 \#446; Fax: (66)2-580-0064; E-mail: titirut.mek@dpu.ac.th

JEL: F42, F53, L15. international quality assessment organizations or other countries have been using widely.

Eurostat (European Statistical System Committee 2011 ) is the office that prepares and provides statistical data of the European Union, with very high quality statistics, whereby quality assurance has been included as a normal process in the preparation of official statistics. It is not the only agency to prepare statistics and, because international statistics among the European Union must be reliable and comparable, a European Statistical Systems (ESS) (European Statistical System 2012) was established to ensure standardization among EU countries. All items for statistical collection will have the same standards, from data collection, computation, as well as dissemination. The focus was formerly on the conformity of statistical data within EU policy and afterwards, on other statistical agencies. Later in 2005, the European Statistical System Committee (ESSC) prepared 15 codes of practice to determine standards for the production of official statistics of member countries to have the same standards as the EU.

The International Monetary Fund (or IMF) was established in 1947 by governments of the alliances countries, and is a specialized agency of the United Nations with a regulation requiring that any member of the World Bank must also be a member of the IMF. Members of the IMF must already be a member of the UN. At present, there are 188 members, with South Sudan as the $188^{\text {th }}$ member, joining on 18 April 2012. Therefore, producing quality assured statistics requires the combined standards from members, such as the UNSD and ESS. The IMF has used the Data Quality Assessment Framework (DQAF) (International Monetary Fund 2003) to assess the quality of the data 
and to monitor the system and process, whereby the IMF emphasizes statistical results must have the required quality.

In general, each country in the world has their own statistical office. However, developed countries often have a good official statistics system and management that will finally lead to standardized official statistics and quality. Therefore, in 2015, the National Statistics Office asked the researcher to prepare a statistics management system and establish a code of conduct to manage Thailand's official statistics.

As discussed above, the tools used for successful management of quality assurances in each country should comprise a Code of Practice with general indicators, a Quality Assurance Framework, QAF that specifies details for implementation at the level of the institution and the level of survey/product of official statistics. The indicators should be used to build a Quality Model and should conform to the Generic Statistical Business Process Model (version 4.0) (GSBPM).

In the next section, the background of official statistics management system and the Quality Assurance Framework for quality assurance management of international organizations is described.

\section{MANAGEMENT SYSTEM FOR OFFICIAL STATISTICS AND A QUALITY ASSURANCE FRAMEWORK FOR MANAGEMENT IN INTERNATIONAL ORGANIZATIONS}

Many national and international organizations use an official statistics management system in quality assurance of its official statistics. There are organizations with complete and clear-cut official statistics management system, while other organizations have partial official statistics management in certain processes. The study focuses on 3 organizations that have internationally accepted official statistics management: United Nations Statistics Division (UNSD), Eurostat, and International Monetary Fund (IMF).

\subsection{United Nations Statistics Division (UNSD)}

UNSD has developed a quality assessment framework called NQAF (The Expert Group on NQAF 2012) that covers the whole process of official statistics management such as official statistics management, organizational environment, production process, and
19 quality dimensions of official statistics production, specifying in detail the indicators of each dimensions to achieve the quality assurance required by the UN.

The 19 quality dimensions are as follows:

(i) Managing the statistical system:

1) Coordinating the national statistics system,

2) Managing relationships with data users and data providers,

3) Managing statistical standards;

(ii) Managing the institutional environment:

4) Assuring professional independence,

5) Assuring impartiality and objectivity,

6) Assuring transparency,

7) Assuring statistical confidentiality and security,

8) Assuring the quality commitment,

9) Assuring adequacy of resources;

(iii) Managing Statistical processes:

10) Assuring methodological soundness,

11) Assuring cost-effectiveness,

12) Assuring soundness of implementation,

13) Managing the respondent burden;

(iv) Managing statistical outputs:

14) Assuring relevance,

15) Assuring accuracy and reliability,

16) Assuring timeliness and punctuality,

17) Assuring accessibility and clarity,

18) Assuring coherence and comparability and

19) Managing metadata.

From 2010, a template from NQAF was developed, showing indicators in detail, covering all dimensions and processes so that organizations can apply the indicators or use them as framework for quality assurances. However, it is not meant to replace or 
change the framework of existing quality assurances of statistical offices in each country as each nation needs. There are differences in the adaptation of the NQAF Template, depending on the development, existing resources, institution environment and the concern for the quality of the production of official statistics at present. Therefore, the national statistics offices of each country do not need to apply all the NQAF indicators.

\subsection{Eurostat}

Eurostat has developed 15 Codes of Practice (European Statistical System Committee 2011; European Statistical System 2012) to create a system for the whole process of official statistic management. It has focused on 4 main issues as NQAF. The code of practice specifies key principles in order to produce quality of official data as required according to EU standard.

The 15 Codes of Practice are:

(i) Institutional Environment:

1) Professional Independence,

2) Mandate for data collection,

3) Adequacy of resources,

4) Commitment to quality,

5) Statistical confidentiality,

6) Impartiality and objectivity;

(ii) Statistical Process:

7) Sound methodology,

8) Appropriate statistical procedures,

9) Non-excessive burden on respondents,

10) Cost effectiveness;

(iii) Statistical Output:

11) Relevance,

12) Accuracy and reliability,

13) Timeliness and punctuality,

14) Coherence and comparability, and

15) Accessibility and clarity.
A Eurostat Quality Assurance Framework (QAF) has also been established that specifies methods at institutional level and/or product/survey level for each of the key principle for actual implementation, which covers principles 4 and 7 to 15 .

Due to Eurostat emphasizing data utilization, therefore, the result of official statistics must have quality in order that users can have confidence in its correction and appropriation.

\subsection{International Monetary Fund}

IMF has developed a data quality assessment tool called DQAF (International Monetary Fund 2003) as a framework for assessing the quality of official statistics data management as a whole process, starting from governance, work system, official statistics production process, as well as the official statistics results, in accordance with IMF role that seek to assess the quality of official statistics production of member countries.

This framework was developed with inputs and technical and financial support from the protection of Basic Services' (PBS) project, specifically from its Monitoring and Evaluation component.

IMF has also determined a framework in assessing the whole official statistics production process such as collection, computation, as well as distribution. The DQAF quality assessment framework is internationally accepted, and is used as a basis to develop quality data assessment in several countries and agencies including World Bank.

DQAF comprises two main parts: Prerequisites that organizations should have in order to prepare quality statistics and Quality dimensions.

Organizations Dimension:

(i) Dimension 0.1 Legal and institutional environment;

(ii) Dimension 0.2 Resources;

(iii) Dimension 0.3 Relevance;

(iv) Dimension 0.4 Other Quality Management.

Quality Dimensions:

(i) Dimension 1.1 Transparency and Ethical standards; 
(ii) Dimension 1.2 Methodological soundness;

(iii) Dimension 1.3 Accuracy and reliability;

(iv) Dimesion1.4 Serviceability; and

(v) Dimension1.5 Accessibility.

In each quality dimension, there are 3-5 subelements, and in each element, there are required indicators. DQAF is thus a general framework that can be applied to all types of data.

3. ESTABLISHING A CODE OF PRACTICE OF THAILAND OFFICIAL STATISTICS FOR QUALITY ASSURANCE MANAGEMENT

\subsection{Establishing a Code of Practice}

Quality assurance of Thailand official statistics should follow these steps:

1) Study the Code of Practice for quality management of official statistics of national or international agencies.

2) Call a meeting and jointly determine Code of Practice and indicators of the code of practice for official statistic quality management in Thailand.

3) Draft of the Code of Practice and indicators of Code of Practice of official statistic quality management in Thailand that conforms with 2).

4) Organize a brain storming session from target group or stake holders to collect the opinion about the Code of Practice and indicators of Code of Practice of official statistic quality management in Thailand.

5) Review and improve the Code of Practice and indicators of Code of Practice of official statistic quality management in Thailand according to the recommendations of target groups and stakeholders.

6) Submit the draft of the Code of Practice and indicators of Code of Practice of official statistic quality management in Thailand to the Subcommittee on Statistical Standards and Academic advisors for comments.

7) Improve the Code of Practice and indicators of Code of Practice of official statistic quality management in Thailand according to the recommendation of the committee/Subcommittee.

\subsection{Process for Creating Quality Official Statistics}

1) Use quality indicators of official statistics item of the code of practice to draw up a questionnaire about weighting/loading of the quality of official statistics items, classified by the source of official statistics, such as indicators of official statistics items from surveys, information from administrative data source, and data from combined sources. These will be used in a questionnaire to survey opinions of personnel of the National Statistics Office of Thailand as the agency concerned in providing statistical data and information to users from all sectors.

2) Collect data about all quality indicators of official statistics using the questionnaire concerning the quality of official statistics in general given to the National Statistics Office personnel and the subcommittee of each statistical branch as 94 persons for the whole country.

3) Analyze data collected from the National Statistics Office personnel and the subcommittee of each statistical branch by using factor analysis and determine factors using principle component analysis, classified by source of the official statistics items. This will be used to create a selfevaluation for official statistics for the 21 branches of statistics producers agencies, to build criteria indicators for quality assurance of official statistics, and to create a quality format of official statistics for Thailand.

\section{RESULTS AND ANALYSIS}

\subsection{Code of Practice: Nine Rules for Quality} Management of Official Statistics in Thailand

From an analysis of quality assurance management, Code of Practice, and Data Quality Framework of national and international organizations that are proven tools that can successfully assist Thailand to achieve its quality assurance management of official statistics, the paper has considered international standards for application that should be also appropriate for Thailand's context. Another factor is the requirement of experts who are well experienced in the Thai official statistics system.

As for the Thai context, elements of official statistics production that must be considered are: personnel potential, adequate budget and technology, and value/worthiness of quality assurance of official 
statistics. Another important factor is the cooperation of all nationwide agencies involved in producing official statistics. The Code of Practice should also determine a small number of "general" indicators so as to encourage cooperation of concerned official statistics production agencies to undertake self-evaluation, and should be adequate to measure quality of Thailand official statistics. The Code of practice for quality management of Thailand official statistics production comprises the following 9 quality dimensions (Phisalbutr, et al. 2013):

The indicators of the Code of Practice are listed in Table 1.

Table 1: The Code of Practice - Nine Rules for Quality Management of Thailand Official Statistics Production

\begin{tabular}{|l|}
\hline The institutional environment \\
\hline Rule 1. Professional and Independence \\
Rule 2. Statistical Confidentiality \\
\hline Statistical processes \\
\hline Rule 3. Sound Methodology \\
Rule 4. Appropriate Statistical Procedures \\
\hline Statistical Output \\
\hline Rule 5. Relevance \\
Rule 6. Accuracy and Reliability \\
Rule 7. Timely and Punctuality \\
Rule 8. Coherence and Comparability \\
Rule 9. Accessibility and Clarity \\
\hline
\end{tabular}

\subsection{Quality of Official Statistics Classified by Source}

The quality format of official statistics items are drawn from the indicators of official statistics items and the importance/weighting of each indicator, that best describes the quality of the official statistics item. The quality indicators of official statistics can be divided into two groups : common indicators not related to specific indicators described by source of official statistics where it was obtained, that is, indicators from surveys, data from administrative data source and combination of data source. The second group is specific indicator groups on acquisition method of above official statistics items.

Common indicators can be used for all sources of official statistics whereas specific indicators can be applied for a fitted source.

From Table 2, the indicator groups of official statistics comprise a total of 35 common indicators.
Moreover, Table 3 shows specific indicators for each of source of data such as data from survey comprising 6 indicators, for administrative data comprising 3 indicators, and for data from a combination of data sources comprising 3 indicators. Therefore, from Tables 2 and 3 we can found that total indicators for each of source of data are such as 41,38 and 38 indicators, respectively.

The weighting/loading of each indicator would depend on the weight value and percentage of the weighting/loading of each indicator when compared with the weighting/loading of total indicators of each source of the official statistics.

\section{SUMMARY: RESEARCH AND RECOMMEN- DATIONS}

From the study, the Code of Practice - Nine rules for quality management in production of official statistics in Thailand are:

(i) The institutional environment:

Rule 1. Professional and Independence;

Rule 2. Statistical Confidentiality.

(ii) Statistical processes:

Rule 3. Sound Methodology;

Rule 4. Appropriate Statistical Procedures.

(iii) Statistical Output:

Rule 5. Relevance;

Rule 6. Accuracy and Reliability;

Rule 7. Timely and Punctuality;

Rule 8. Coherence and Comparability;

Rule 9. Accessibility and Clarity.

The weighting/loading of common indicators of the Code of Practice is shown in Table 2 and are used as weights in the calculation of the score of quality of official statistics.

\section{IMPROVEMENT OF INDICATORS}

In order to evaluate quickly and easily the quality of the official statistic items that contain many indicators and to conform with the evaluative potential of the official statistics units in each branch, both in terms of 
Table 2: Common Indicators and their Weights of Official Statistics Items

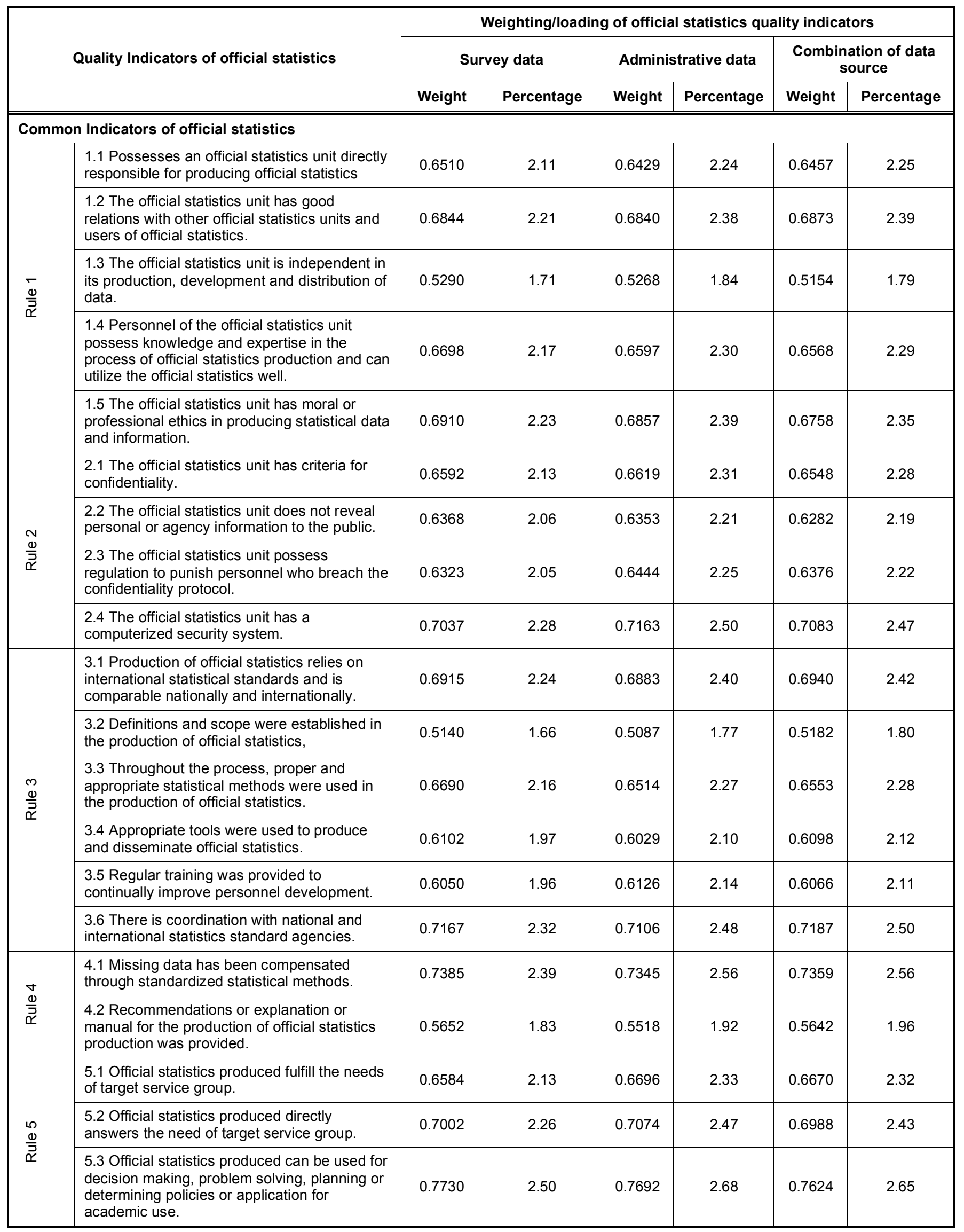


(Table 2). Continued.

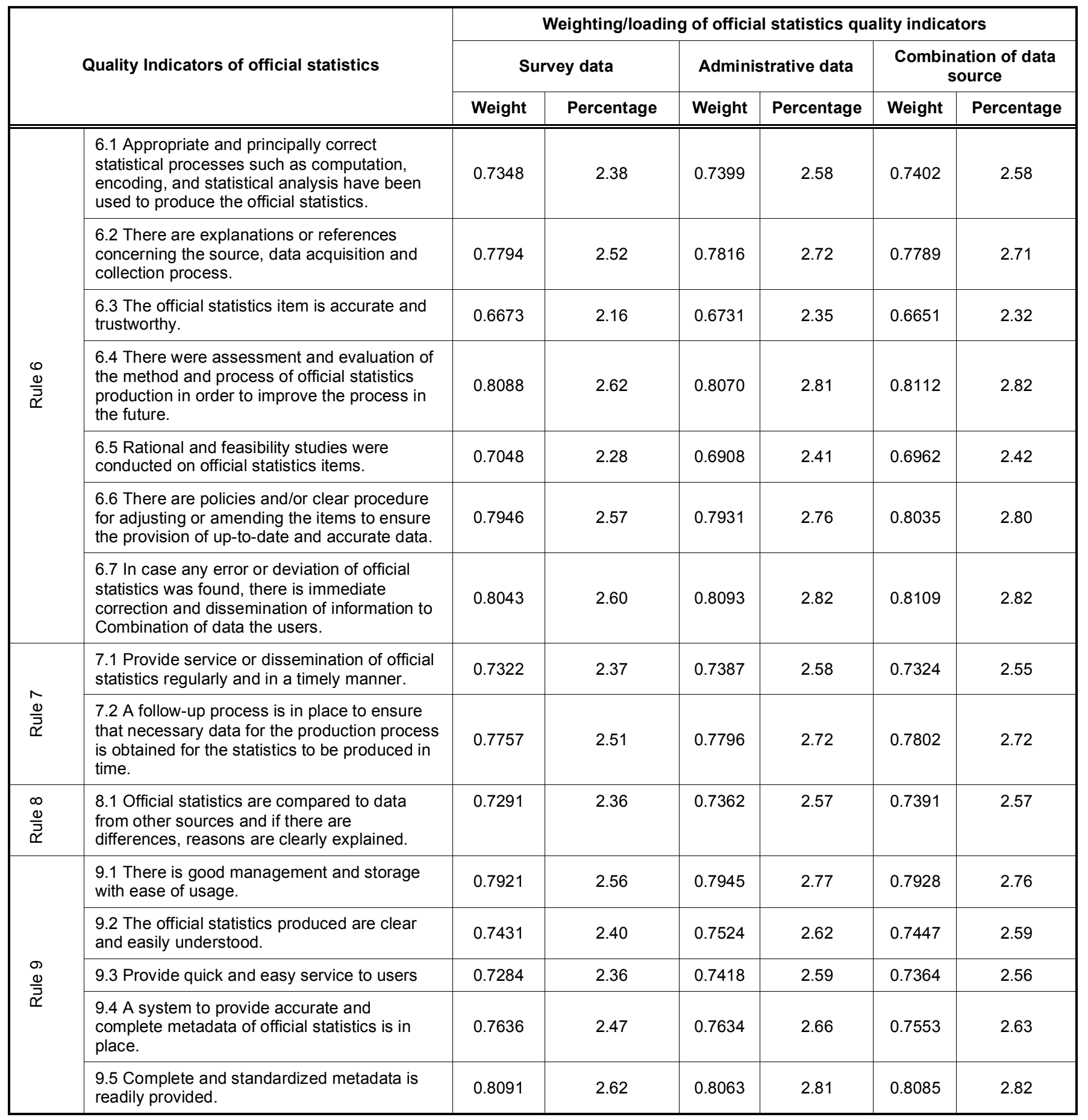

personnel, tools and budget so that they become accurate and trustworthy to a certain level, where the data can be disseminated and used beneficially, the number of the indicators should be reduced. The model proposed is as follows:

Model 1: Include the first 20 general indicators of official statistics that are the most important has the most weighting and specific indicator groups.
Model 2: Important indicators with weightings for indicators of high quality of official statistics.

Model 3: Indicators that are important, with weighting for indicators of quite high quality of official statistics.

Model 4: Include the first 26 general indicators of official statistics that are the most important and/or has 
Table 3: Specific Indicators and their Weights of Official Statistics

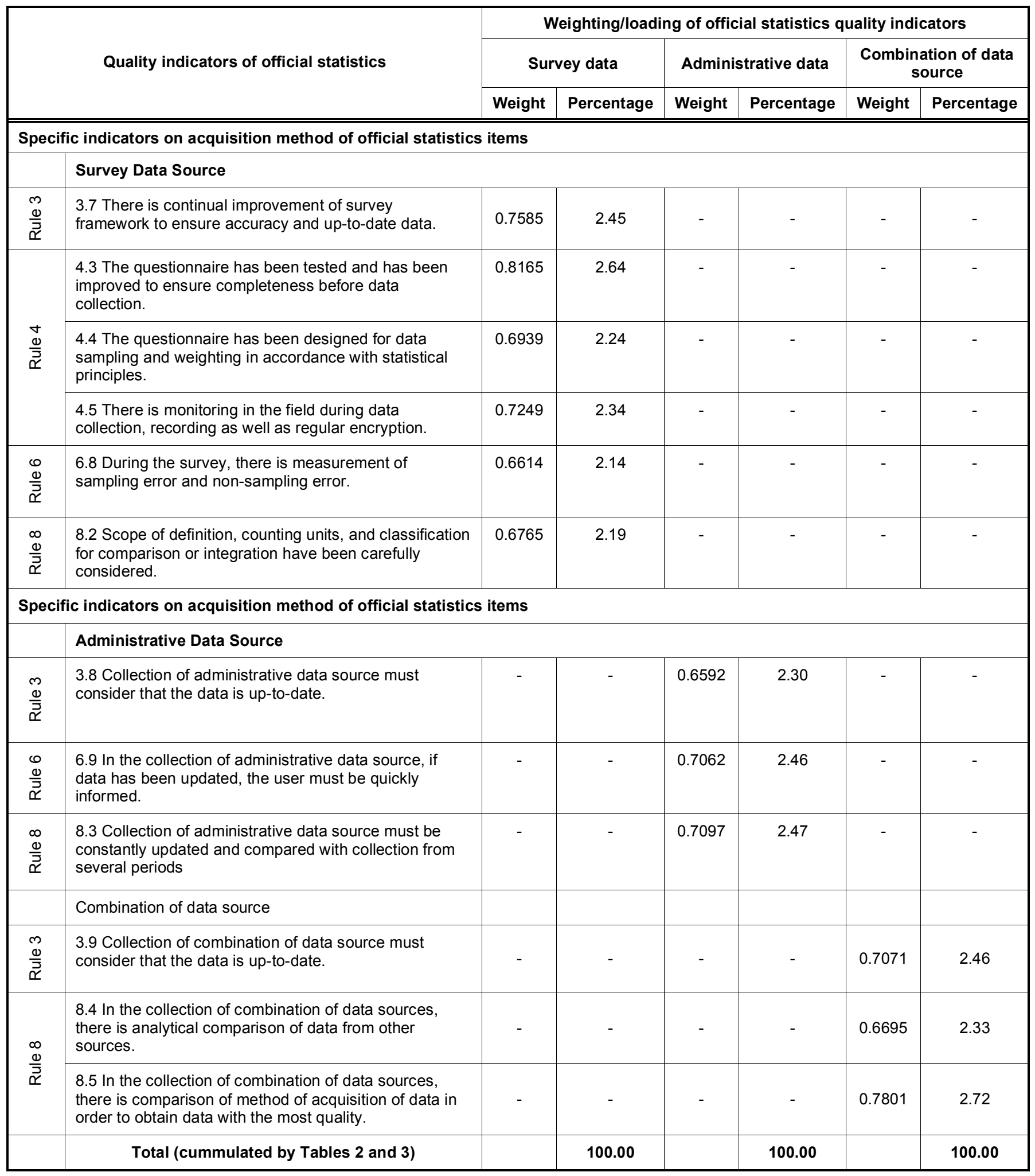

the most weighting and specific indicators groups that cover all 9 rules of the Code of Practice of quality management of the official statistics.
ACKNOWLEDGEMENT

This research was undertaken with funding from the National Statistics Office of Thailand based on the 
"Development of Official Statistics and Statistical Information of Thai Government Office 21 Branches" project. The authors wish to acknowledge the helpful comments and suggestions of Chia-Lin Chang and Michael McAleer.

\section{REFERENCES}

The Expert Group on NQAF (2012). Guidelines for the template for A Generic National Quality Assurance. N.P: n.p.
European Statistical System Committee (2011). EUROPEAN STATISTICS CODE OF PRACTICE. N.P: n.p.

European Statistical System (2012). Quality Assurance Framework of the European Statistical System. N.P: n.p.

International Monetary Fund (2003). Data Quality Assessment Framework (DQAF) for Monetary Statistics. Washington, DC, USA: International Monetary Fund.

Phisalbutr, S., Mekbunditkul, T. and Kamdits, S (2013). Development of Official Statistics and Statistical Information of Thai Government Office 21 Branches. Bangkok, Thailand: National Statistics Office.

DOI: https://doi.org/10.6000/1929-7092.2017.06.23

(C) 2017 Mekbunditkul and Phisalbutr; Licensee Lifescience Global.

This is an open access article licensed under the terms of the Creative Commons Attribution Non-Commercial License (http://creativecommons.org/licenses/by-nc/3.0/) which permits unrestricted, non-commercial use, distribution and reproduction in any medium, provided the work is properly cited. 